\title{
Volatility Interactions among India and US Stock Markets
}

\author{
Joshi Prashant \\ Professor and Head, Department of Management \\ UKA Tarsadia University, India \\ E-mail: joshiprashantm@gmail.com
}

Received: April 16, 2014 Accepted: June 2, 2014 Published: June 19, 2014

doi:10.5296/csbm.v1i1.5830 URL: http://dx.doi.org/10.5296/csbm.v1i1.5830

\begin{abstract}
The study examines the return and volatility spillover among BSE and DJIA of India and US Stock Markets respectively. It employed GARCH-BEKK model to examine the relationship. The period of study is from January 2, 2012 to April 4, 2014. We find evidences of bidirectional shock and volatility interactions among the stock markets. The results indicate that DJIA exercises more influence on BSE in terms of shocks and volatility transmission. The overall persistence of volatility is highest in US stock market.
\end{abstract}

Keywords: Return and volatility spillovers, Unit root test, Multivariate GARCH model 


\section{Introduction}

The growing international integration of financial markets has prompted several empirical studies to examine the mechanism through which stock market movements are transmitted around the world. These studies evaluate how stock returns in one national stock market influence the returns of other stock markets. These studies further examine their implications for pricing securities, for hedging, other trading strategies and for framing regulatory policies. These issues have been of heightened interests to all the participants in the stock markets in the wake of October 1987 international crash of stock markets that saw large correlated price movements across most of the stock markets of the world. It has lead to introduction of various regulations and institutional rules to dampen the cross-market impact of large stock movements.

The extent of the global linkage of emerging markets improves access to the international capital markets. Strong global linkage reduces the insulation of the emerging stock markets from external shocks, hence limiting the scope for independent monetary policy (Li \& Majerowska, 2007). From the perspective of the global investors, weak stock market linkage in the form of less than perfect correlation between their returns offers potential gains from international portfolio diversification, while strong market linkage or co-movement in returns eliminates the potential benefits of diversification.

Although there is no dearth of literature on financial integration, there are only a few studies related to volatility interactions between stock markets of India and US. Moreover, the limited literature on the stock markets in Asia has studied the co-movements between the stock markets using cointegration and Vector Autoregression framework (Eun \& Shin, 1989; Chung \& Ng, 1992; Bhattacharya \& Samantha, 2001; Wong, Agrawal, \& Du, 2005; Voronkova, 2004; Ahmad, Ashraf, \& Ahmed, 2005; Cheeley \& Steeley, 2005; Yang, Hsiao, Li, \& Wang, 2006; Hoque, 2007). The studies do not take into account the interactions in terms of volatility among the markets. The present study attempts to examine volatility interactions between India and US stock markets.

\section{Literature Review}

It is believed that if markets are integrated, an unanticipated event in one market will influence not only returns but also variance in the other markets. The analysis of volatility is particularly important because it can proxy for the risk of assets. Scheicher (2001) studied the regional and global integration of stock markets in terms of return and volatility shocks in Hungary, Poland and Czech Republic and Financial Times/S\&P's world actuaries index by using MGARCH (Multivariate Generalized Auto regressive conditional heteroscedasticity) with a constant conditional correlation. Using daily closing price values of the stock markets from January 1, 1995 to October 7, 1997, results revealed that the emerging stock exchanges were integrated with the global market, proxied by Financial Times/S\&P's actuaries' world index only in terms of return. MGARCH results showed that the regional influences were the major cause of volatility of the markets. International volatility had no impact on the markets.

Chou, Lin and Wu (1999) examined the price and volatility linkages of Taiwan stock market 
with United States using close-to-open, open-to-close and close-to-close returns of indices of Taiwan known as Taikex and United states' Standard and Poor's 500 (S\&P 500) composite index during January 1, 1991 to December 31, 1994. The results found that the volatility and return spilt over from US to Taiwan. The results of MGARCH indicated some important linkage from the US stock market to the Taiwan stock market. The spillover effects occurred for both the mean and the variance of Taiwan Stock returns. It further pointed out that the volatility in US stock markets affected total daily volatilities of the Taiwan stock market.

Karolyi (1995) examined the short run dynamics of returns and volatilities for stocks traded on the New York Stock Exchange (NYSE) and Toronto stock exchange (TSE) of Canada by applying multivariate GARCH and Vector autoregression models in time series of daily stock market indices at the close of markets in terms of local currency for S\&P 500 and TSE 300 during April 1, 1987 to December 29, 1989. Results of MGARCH indicated the return and volatility spillovers from S\&P 500 to TSE 300 . The effects of shocks of return and volatility from NYSE to TSE measured by MGARCH were smaller and less persistent.

Harris and Pisedtasalasai (2006) applied constant conditional correlation MGARCH framework to investigate return and volatility spillover effects between the Financial Times Stock Exchange (FTSE)100, FTSE 200 and FTSE small cap equity indices of UK stock market using daily return during January 1, 1986 to December 2002 using GJR specifications of MGARCH model to capture asymmetric effect. The study found that return and volatility transmission mechanism between large and small stocks in the UK were asymmetric. There were significant positive spillover effects from portfolio of larger stocks to the portfolio of smaller stocks.

Worthington and Higgs (2004) examined the transmission of equity returns and volatility among three developed Asian markets (Hong Kong, Japan and Singapore) and six emerging markets of Asia (Indonesia, Korea, Malaysia, the Philippines, Taiwan and Thailand) using weekly returns from January 15, 1988 to October 6, 2000. They employed BEKK (Baba, Engle, Kraft and Kroner) parameterization of multivariate GARCH model to identify the source and magnitude of volatility spillover. The study found the presence of positive mean and volatility spillovers. The mean return spillovers from the developed markets to the emerging markets were not homogenous across the emerging markets. Application of MGARCH suggested that own stock market volatility spillovers were generally higher than cross-volatility spillovers for all markets, especially for emerging stock markets. Li (2007) examined the linkages between the two emerging stock exchanges namely Shanghai and Shenzen of China and the established stock markets Heng Seng of Hong Kong and S \& P of the US by a multivariate GARCH-BEKK framework using the daily share price indices of the stock markets, January 4, 2000 to August 17, 2005. The results indicated that there was no evidence of spillover effect in terms of return and volatility between the stock exchanges in China and US market. There was an evidence of unidirectional volatility spillover from stock exchange in Hong Kong to those in Shanghai and Shenzhen. The study found that Chinese stock exchanges were integrated with the regional developed stock exchange in Hong Kong but the extent of the linkages between the stock exchange in Hong Kong and China was weak. The results further showed that there was a bidirectional shock spillover between the two 


\section{Macrothink}

Chinese stock exchanges. The study also found that there was an asymmetric response of volatility in all four stock exchanges under study.

Although there is a voluminous literature on equity markets integration internationally, little research has been undertaken to study the interdependence structure of the Indian and US stock markets using MGARCH-BEKK model. In the light of the review of the existing literature on the linkages between the various stock markets, the present study tries to analyze volatility transmission among India and US markets using MGARCH-BEKK framework. The rest of the paper is organized as follows. Data and Preliminary Analysis are presented in Section 3. Section 4 provides research design used in the study. Empirical results are discussed in Section 5. Section 6 summarizes.

\section{Data and Preliminary Analysis}

The study uses data on daily closing price of Sensex of BSE (Bombay Stock Exchange) and DJIA (Dow Jones Industrial Average) of US from January 2012 to April 4,2014. Yahoo Finance data base is used to analyze the volatility of the stock markets. The period is the most recent one to examine the volatility interactions among the stock markets. Daily returns are identified as the first difference in the natural logarithm of the closing index value for the two consecutive trading days for the six indices.

Figure 1 presents time plot of the price series of the stock markets. The first impression is that all the indices follow a similar movement. Overall, all the stock price indices are trending upwards during the recent time.

Figure 2 represents the returns of the share price indices, the first difference of the natural logarithm of the share price indices, during the period under study. All indices are characterized by volatility clustering where large (small) volatility followed by large (small) volatility. As the cluster tends to occur simultaneously, between the indices, volatility must be modeled systematically.

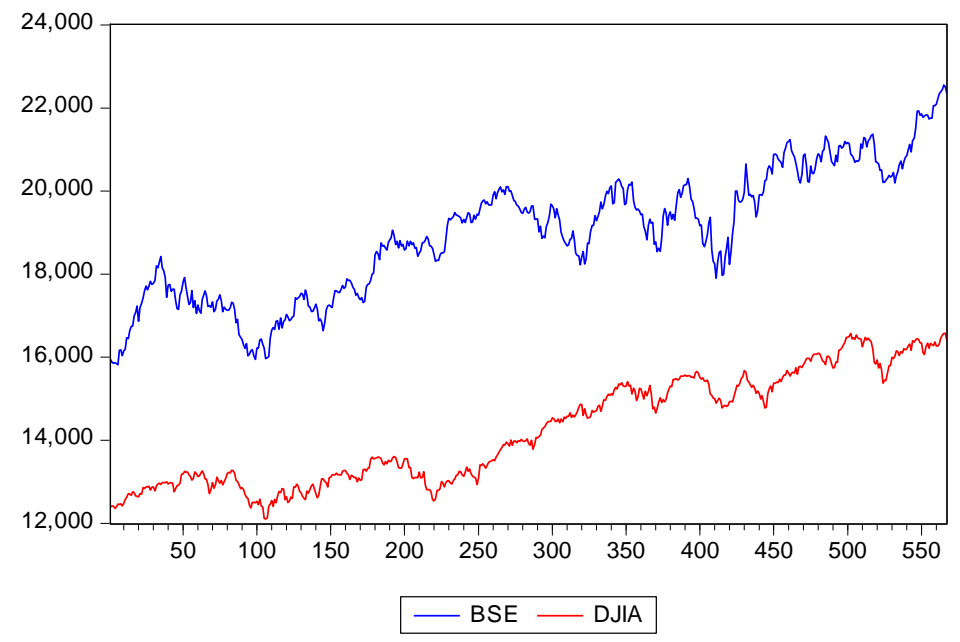

Figure 1. Stock indices during year 2012 to year 2014 


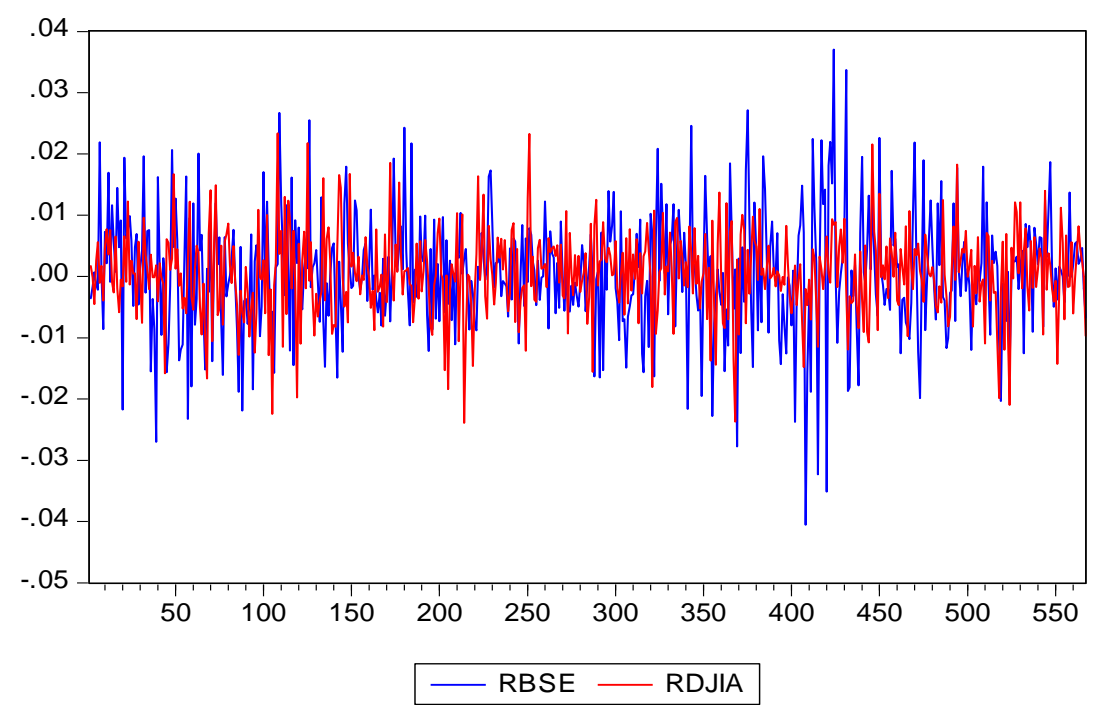

Figure 2. Returns of the share price indices

Table 1 reports the summary statistics for the return series.

Table 1. Summary statistics of returns series

\begin{tabular}{lll}
\hline Summary Statistics & RBSE & RDJIA \\
\hline Mean & 0.000598 & 0.000496 \\
Median & 0.000856 & 0.000352 \\
Std. Dev. & 0.00975 & 0.006949 \\
Skewness & -0.08182 & -0.15377 \\
Kurtosis & 4.370828 & 4.052791 \\
Jarque-Bera & 44.94855 & 28.36942 \\
Probability & 0.000 & 0.000 \\
\hline
\end{tabular}

The performance of the indices as measured by the average return is better in Indian stock markets. It exhibits higher volatility than DJIA. The Jarque-Bera statistics reject the null hypothesis that the returns are normally distributed for all cases. Stock indices have negative skewness, indicating that large negative stock returns are more common than large positive returns. Furthermore all the returns series are leptokurtic, having significantly fatter tails and higher peaks which can be seen from the kurtosis statistics that are greater than 3 . Generalized Autoregressive Conditional Heteroscedasticity (GARCH) models are capable of dealing with data displaying the above features. When modeling with $\mathrm{GARCH}$, the nonzero skewness statistics indicate an $\mathrm{ARCH}$ order higher than one in the conditional variance equation. Subsequently, a Multivariate $\operatorname{GARCH}(1,1)$ model should be preferred to an $\mathrm{ARCH}(p)$ model to examine volatility interactions effects for the sake of parsimony ( $\mathrm{Li}$, 2007). 


\section{Macrothink}

\section{Methodology}

On the basis of the features discussed in the previous section, GARCH model is appropriate for the study. The aim of the paper is to examine the interdependence across both the stock markets. The following model is used for return series of the share price indices under study.

$$
\begin{aligned}
& Y_{t}=\alpha+\Gamma Y_{t-1}+\varepsilon_{t}, \\
& \varepsilon_{t} / I_{t-1} \approx N\left(0, H_{t}\right)
\end{aligned}
$$

Where $Y_{t}$ is a $2 \times 1$ vector of daily returns at time $t$ and $\Gamma$ is a $2 \times 2$ matrix for parameters associated with the lagged returns. Lag length selection criteria suggest AR(1) model for return series. The $2 \times 1$ vector of random error, $\varepsilon_{t}$, is the innovation for each market at time $t$ and has a $2 \times 2$ conditional variance-covariance matrix, $H_{t}$. The market information available at time $\mathrm{t}-1$ is represented by the information set $\mathrm{I}_{\mathrm{t}-1}$. The $2 \times 1$ vector of $\alpha$ represents constants. Bollerslev et al. (1988) propose that $\mathrm{H}_{\mathrm{t}}$ is a linear function of the lagged squared errors and cross products of errors and lagged values of the elements of $H_{t}$ as follows: The variance-covariance matrix $\mathrm{H}_{t}$ is presented below:

$$
\operatorname{vech}\left(H_{t}\right)=\operatorname{vech}(C)+\sum_{i=1}^{q} A_{i} \operatorname{vech}\left(\varepsilon_{t-1} \varepsilon_{t-i}^{\prime}\right)+\sum_{i=1}^{p} G_{i} \operatorname{vech}\left(H_{t-i}\right)
$$

Where vech is the operator that stacks the lower triangular portion of a symmetric matrix into a vector. The problems with this formulation are that the number of parameters to be estimated is large and restrictions on the parameters are needed to ensure that the conditional variance matrix is positive definite. Engle and Kroner (1995) propose the following new parameterization for $\mathrm{H}_{\mathrm{t}}$, i.e. the BEKK model, to overcome the above two problems.

$$
H_{t}=C^{\prime} C+A^{\prime} \varepsilon_{t-1}^{\prime} \varepsilon_{t-1} A+G^{\prime} H_{t-1} G
$$

The BEKK model provides cross-market effects in the variance equation parsimoniously and also guarantees positive semi-definiteness by working with quadratic forms.

The notion used in the equation is as follows:

$\mathrm{C}$ is $2 \times 2$ lower triangular matrix of constants while $\mathrm{A}$ and $\mathrm{G}$ are $2 \times 2$ matrices. The diagonal parameters of matrices $A$ and $G$ measures the effects of own past shocks and past volatility of market $i$ on its conditional variance. The off-diagonal parameters in matrices $A$ and $G, a_{i j}$ and $\mathrm{g}_{\mathrm{ij}}$, measure the cross-market effects of shock and volatility, also known as volatility spillover. $\mathrm{H}_{\mathrm{t}}$ is a variance-covariance matrix. We will use Multivariate GARCH in the style of BEKK proposed by Engle and Kroner (1995) to analyze volatility spill over among the stock markets.

The BEKK systems can be estimated using maximum likelihood method. The log likelihood function of the joint distribution is the sum of all the log likelihood functions of the 


\section{Macrothink}

conditional distributions, i.e. the sum of the logs of multivariate-normal distribution. Letting $\mathrm{L}_{\mathrm{t}}$ be the $\log$ likelihood of observation $\mathrm{t}, \mathrm{n}$ be the number of stock exchanges and $\mathrm{L}$ be the joint log likelihood which gives,

$$
L=\sum_{i=1}^{T} L_{t} \quad L_{t}=n / 2 \ln (2 \pi)-\frac{1}{2} \ln \left|H_{t}\right|-\frac{1}{2} \varepsilon_{t}^{\prime} H_{t}^{-1} \varepsilon_{t}
$$

\section{Empirical Results}

In this section, we perform unit root test to check for nonstationarity of the stock markets series. We report the estimated results about market linkages. We will look for any statistically significant cross-market effects as evidence of linkages and measures the extent of the linkages by the estimated time-varying covariances using MGARCH asymmetric model. We organize the section as follows. In section 5.1, we discuss Augmented Dickey Fuller Test (ADF) results. In section 5.2, we report the evidence of market linkages in the estimated six-variable asymmetric GARCH-BEKK model.

\subsection{Unit Root Test Results}

Stationarity conditions of the stock market indices are tested by Augmented Dickey-Fuller Test (ADF). A unit root test is a statistical test for the proposition that in an autoregressive statistical model of a time series, the autoregressive parameter is one. It is a test for detecting the presence of stationarity in the series. The early and pioneering work on testing for a unit root in time series was done by Dickey and Fuller (Dickey \& Fuller, 1979; Fuller, 1981). If the variables in the regression model are not stationary, then it can be shown that the standard assumptions for asymptotic analysis will not be valid. In other words, the usual "t-ratios" will not follow a t-distribution; hence they are inappropriate to undertake hypothesis tests about the regression parameters.

Stationarity time series is one whose mean, variance and covariance are unchanged by time shift. Nonstationary time series have time varying mean or variance or both. If a time series is nonstationary, we can study its behaviour only for a time period under consideration. It is not possible to generalize it to other time periods. It is, therefore, not useful for forecasting purpose.

The presence of unit root in a time series is tested with the help of Augmented Dickey-Fuller Test. It tests for a unit root in the univariate representation of time series. For a return series $\mathrm{R}_{\mathrm{t}}$, the ADF test consists of a regression of the first difference of the series against the series lagged $\mathrm{k}$ times as follows:

$$
\begin{gathered}
\Delta r_{t}=r_{t}-r_{t-1} ; r_{t}=\ln \left(R_{t}\right) \\
\Delta r_{t}=\alpha+\delta r_{t-1}+\sum_{i=1}^{p} \beta_{i} \Delta r_{t-i}+\varepsilon_{t}
\end{gathered}
$$




\section{Mll Macrothink}

The null hypothesis is H0: $\delta=0$ and H1: $\delta<1$. The acceptance of null hypothesis implies nonstationarity.

We can transform the nonstationary time series to stationary time series either by differencing or by detrending. The transformation depends upon whether the series are difference stationary or trend stationary. We report the results of unit root test in Table 2.

Table 2. Unit root test results

\begin{tabular}{lll}
\hline Stock markets & Level & Return series \\
\hline BSE & -1.390 & -22.64 \\
DJIA & -0.681 & -23.90 \\
\hline
\end{tabular}

Note. Mackinnon's test critical values at $1 \%, 5 \%$ and $10 \%$ are $-3.439,-2.865$ and -2.568 respectively.

ADF statistics reported in the Table 2 show that the null hypothesis of a unit root in case of the indices is rejected. The absolute computed values for all the indices are higher than the MacKinnon critical value at $1 \%$ level. Thus, the results show that the return series are stationary. As the results suggest that the underlying return series are stationary, our next step is to examine the stock markets' linkages.

\subsection{The Evidence of Volatility Linkages of Stock Markets}

Now, we examine the estimated results of the time varying variance-covariance Equation 3 in the system. The results of two-variable asymmetric GARCH model are reported in Table 3.

Table 3. Estimated coefficients for MGARCH

\begin{tabular}{|l|l|l|}
\hline Parameter & BSE $(\mathrm{i}=1)$ & DJA $(\mathrm{i}=2)$ \\
\hline $\mathrm{a}_{\mathrm{i} 1}$ & $0.281(0.00)$ & $-0.349(0.00)$ \\
\hline $\mathrm{a}_{\mathrm{i} 2}$ & $0.090(0.00)$ & $0.109(0.00)$ \\
\hline $\mathrm{g}_{\mathrm{i} 1}$ & $0.809(0.00)$ & $0.505(0.00)$ \\
\hline $\mathrm{g}_{\mathrm{i} 2}$ & $0.230(0.00)$ & $0.901(0.00)$ \\
\hline Multvariate ARCH test & $11.32(0.25)$ & \\
\hline LB-Qs(12) & $9.54(0.08)$ & \\
\hline $\begin{array}{l}\text { Multivariate } \\
\text { Q statistics(12) }\end{array}$ & $48.37(0.17)$ & \\
\hline
\end{tabular}

Now we examine the estimated results. It can be noted that the Ljung Box Q statistics for the 12 the order and Multvariate Q statistics for 12th orders in standardized and squared standardized 
residuals show that there is no series dependence in the residuals indicating the appropriateness of the fitted variance-covariance equations by the two variable asymmetric BEKK model. The matrices $A$ and $G$ reported in Table 3 help us to examine the relationship in terms of volatility. The diagonal elements in matrix A capture the ARCH effect, while the diagonal elements in matrix $G$ measure the GARCH effect. As shown in Table 3, the estimated diagonal parameters $a_{11}$ through $a_{22}$ are statistically significant implying presence of $A R C H$ effect in the stock markets while parameters $g_{11}$ through $g_{22}$ are all statistically significant, indicating a strong GARCH $(1,1)$ process driving the conditional variances of all the indices. The magnitude of own volatility presented by GARCH parameter is highest in DJIA suggesting own volatility largely affect their conditional variance.

The off-diagonal elements of matrix A and G capture the cross-market effects such as shock spillover and volatility spillover among the two stock exchanges. Firstly, we find evidence of statistically significant bidirectional shock transmissions between BSE and DJIA as the pairs of off-diagonal parameters $\mathrm{a}_{12}$ and $\mathrm{a}_{21}$ are statistically significant. The two way shock spillover indicates strong connection between the stock markets. The bidirectional shock spillover indicates the news about shocks in one stock exchange affect the volatility of other stock exchange and vice-versa. In terms of cross-shock spillover effects in the markets, past innovations in DJIA have the greatest effect (0.349) on future volatility in BSE. The negative coefficient of A mean that the variance is affected more when the shocks move in opposite direction than when they move in the same direction.

Secondly, there are bidirectional volatility linkages between BSE and DJIA as respective coefficients in $g$ are statistically significant. It indicates that the conditional variance of one index depends on past volatility of the other index, implying strong linkages between them. Again, volatility in DJIA has stronger influence of 0.505 on future volatility of BSE while volatility in BSE has the effect of 0.230 on future volatility of DJIA. Own-volatility spillovers in all markets are large and significant. The overall persistence of stock market volatility is highest for DJIA of 0.901 .

\section{Summary}

The study investigates volatility interaction effects between the stock markets of India and US. Summary statistics of returns series of all the stock exchanges suggest that they are leptokurtic, having significantly fatter tails and higher peaks. Generalized Autoregressive Conditional Heteroscedasticity $(\mathrm{GARCH})$ models are capable of dealing with the property of the data.

By applying a multivariate GARCH approach to the daily stock indices, the study found linkages in terms of shocks and volatility. There are evidences of bidirectional shock transmissions between BSE and DJIA. In terms of cross-shock spillover effects in the markets, past innovations in DJIA have the greatest effect of 0.349 on future volatility in BSE. There are bidirectional volatility linkages between BSE and NSE. DJIA has greater influence on future volatility of BSE. The overall persistence of stock market volatility is highest for DJIA. Future research can be undertaken to examine the asymmetric volatility responses 
among the stock markets.

\section{References}

Ahmad, Ashraf, \& Ahmed. (2005). Is the Indian stock market integrated with the US and Japanese stock markets?: An empirical analysis. South Asia economic journal, 193-206. http://dx.doi.org/10.1177/139156140500600202

Bhattacharya \& Samanta. (2001). A tale of two indices: the story of the NASDAQ and The Sensex. Journal of Quantitative Economics, 1(1), 89-102.

Bollerslev, Engle, \& Wooldridge. (1988). A capital asset pricing model with time-varying covariances. Journal of political economy, 96, 116-131. http://dx.doi.org/10.1086/261527

Brooks, C. (2008). Introductory Econometrics for Finance (2nd ed.). Cambridge University Press, UK. http://dx.doi.org/10.1017/cbo9780511841644

Chelley \& Steeley. (2005). Modeling equity market integration using smooth transition analysis: a study of eastern European stock markets. Journal of International Money and Finance, 24, 818-831. http://dx.doi.org/10.1016/j.jimonfin.2005.04.007

Chou, Lin, \& Wu. (1999). Modeling the Taiwan stock market and international linkages. Pacific Economic Review, 4, 305-320. http://dx.doi.org/10.1111/1468-0106.00081

Chung, Y. W., \& Ng, L. (1992). Interactions Between the U.S. and Japan Stock Market Indices. Journal of International Financial Markets, Institutions and Money, 2(2), 51-69.

Dickey, D., \& Fuller, W. (1979). Distribution of the estimates for Autoregressive time series with a unit root. Journal of American Statistical Association, 74, 427-31. http://dx.doi.org/10.1080/01621459.1979.10482531

Dickey, D., \& Fuller, W. (1981). Likelihood Ratio Statistics for Autoregressive Time Series with a Unit Root. Econometrica, 49,1057-72. http://dx.doi.org/10.2307/1912517

Engle \& Kroner. (1995). Multivariate simultaneous generalized ARCH. Econometric Theory, 11, 122-150. http://dx.doi.org/10.1017/s0266466600009063

Eun, C., \& Shim, S. (1989). International Transmission of Stock Market Movements. Journal of Financial and Quantitative Analysis, 24(2), 241-255. http://dx.doi.org/10.2307/2330774

Harris \& Pisedtasalasai. (2006). Return and volatility spillovers between large and small stocks in the UK. Journal of Business Finance and Accounting, 1-16. http://dx.doi.org/10.1111/j.1468-5957.2006.00635.x

Hogue. (2007). Co-movement of Bangladesh stock market with other markets: cointegration and error correction approach. Managerial Finance, 33(10), 810-820. http://dx.doi.org/10.1108/03074350710779250

Karolyi. (1995). A Multivariate GARCH model of international transmissions of stock returns and volatility: The case of the United States and Canada. Journal of Business and Economic Studies, 13(1),11-24. http://dx.doi.org/10.1080/07350015.1995.10524575 


\section{Macrothink}

Kroner, K., \& Ng, V. (1998). Modeling asymmetric comovements of asset returns. The review of Financial Studies, 11, 817-44. http://dx.doi.org/10.1093/rfs/11.4.817

Li. (2007). International Linkages of the Chinese stock exchanges: a multivariate GARCH analysis. Applied Financial Economics, 17, 285-295. http://dx.doi.org/10.1080/09603100600675557

Ng, T. (2002). Stock Price Movements in South-East Asia. Asian Economic Journal, 16(4), 353-77. http://dx.doi.org/10.1111/1467-8381.00157

Scheicher. (2001). The comovements of stock markets in Hungary, Poland and the Czech Republic. International Journal of Finance and Economics, 6, 27-39. http://dx.doi.org/10.1002/ijfe.141

Voronkova. (2004). Equity market integration in Central European stock markets: A cointegration analysis with shifting regimes. International Review of Financial Analyst, 13, 633-647. http://dx.doi.org/10.1016/j.irfa.2004.02.017

Wong, W. K., \& Agarwal, A., \& Jun, D. (2005). Financial Integration for India Stock Market, a Fractional Cointegration Approach. Departmental Working Papers wp501, National University of Singapore, Department of Economics.

Worthington \& Higgs. (2004). Transmission of Equity returns and volatility in Asian developed and emerging markets: A multivariate GARCH analysis. International Journal of Finance and Economics, 9, 71-80. http://dx.doi.org/10.1080/13504850410001674830

Yang, Hsiao, Li, \& Wang. (2006). The emerging market crisis and stock market linkages: Further Evidence. Journal of Applied Econometrics, 21, 727-744. http://dx.doi.org/10.1002/jae.889

\section{Copyright Disclaimer}

Copyright reserved by the author(s).

This article is an open-access article distributed under the terms and conditions of the Creative Commons Attribution license (http://creativecommons.org/licenses/by/3.0/). 